\title{
Olefin Hydroformylation by Sol-gel Entrapped Rhodium Catalysts Bearing Hydrolysable Ligands
}

\author{
José Daniel Ribeiro de Campos and Regina Buffon" \\ Instituto de Química, Universidade Estadual de Campinas, CP 6154, 13084-971 Campinas - SP, Brazil
}

\begin{abstract}
Complexos de ródio preparados in situ a partir de $[\mathrm{Rh}(\mathrm{OMe})(\mathrm{COD})]_{2},\left[\mathrm{Rh}(\mathrm{CO})_{2}(\mathrm{acac})\right]$, $[\mathrm{Rh}(\mathrm{cod})(\mathrm{acac})]$ ou $\left[\mathrm{Rh}(\mathrm{cod})\left(\mathrm{PPh}_{3}\right)_{2}\right]^{+} \mathrm{BPh}_{4}{ }^{-}$com ligantes como $\mathrm{HS}\left(\mathrm{CH}_{2}\right)_{3} \mathrm{Si}(\mathrm{OMe})_{3}$, $\mathrm{Ph}_{2} \mathrm{P}\left(\mathrm{CH}_{2}\right)_{2} \mathrm{~S}\left(\mathrm{CH}_{2}\right)_{3} \mathrm{Si}(\mathrm{OMe})_{3}$ ou $\mathrm{Ph}_{2} \mathrm{P}\left(\mathrm{CH}_{2}\right)_{2} \mathrm{Si}(\mathrm{OMe})_{3}$ foram imobilizados em matrizes de sílica, inorgânicas ou híbridas, pelo processo sol-gel. As matrizes inorgânicas foram preparadas apenas com tetrametilortossilicato enquanto que para as híbridas foram utilizados 1,4-bis(trietoxissilil)benzeno ou 1,2-bis(trietoxissilil)etano como agentes de co-condensação. O sistema baseado em $\left[\mathrm{Rh}(\mathrm{CO})_{2}(\mathrm{acac})\right] / \mathrm{Ph}_{2} \mathrm{P}\left(\mathrm{CH}_{2}\right)_{2} \mathrm{~S}\left(\mathrm{CH}_{2}\right)_{3} \mathrm{Si}(\mathrm{OMe})_{3}$ foi ativo na hidroformilação de 1-hexeno e de 1-octadeceno sem lixiviação de ródio. Também pôde ser usado na ausência de solvente, como observado na hidroformilação do 1-deceno. Apesar do melhor sistema obtido apresentar uma matriz microporosa, não foi possível estabelecer uma correlação direta entre composição da matriz, grau de condensação da mesma e propriedades da superfície.
\end{abstract}

Rhodium complexes prepared in situ from $[\mathrm{Rh}(\mathrm{OMe})(\mathrm{COD})]_{2},\left[\mathrm{Rh}(\mathrm{CO})_{2}(\mathrm{acac})\right],[\mathrm{Rh}(\mathrm{cod})(\mathrm{acac})]$ or $\left[\mathrm{Rh}(\mathrm{cod})\left(\mathrm{PPh}_{3}\right)_{2}\right]^{+} \mathrm{BPh}_{4}^{-}$with ligands as $\mathrm{HS}\left(\mathrm{CH}_{2}\right)_{3} \mathrm{Si}(\mathrm{OMe})_{3}, \mathrm{Ph}_{2} \mathrm{P}\left(\mathrm{CH}_{2}\right)_{2} \mathrm{~S}\left(\mathrm{CH}_{2}\right)_{3} \mathrm{Si}(\mathrm{OMe})_{3}$ or $\mathrm{Ph}_{2} \mathrm{P}\left(\mathrm{CH}_{2}\right)_{2} \mathrm{Si}(\mathrm{OMe})_{3}$ were immobilized in inorganic and hybrid silica matrices via the sol-gel process. The inorganic matrices were prepared with tetramethylorthosilicate while for the hybrid ones 1,4-bis(triethoxysilyl)benzene or 1,2-bis(triethoxysilyl)ethane were used as co-condensation agents. The system based on $\left[\mathrm{Rh}(\mathrm{CO})_{2}(\mathrm{acac})\right] / \mathrm{Ph}_{2} \mathrm{P}\left(\mathrm{CH}_{2}\right)_{2} \mathrm{~S}\left(\mathrm{CH}_{2}\right)_{3} \mathrm{Si}(\mathrm{OMe})_{3}$ was active in the hydroformylation of 1-hexene and 1-octadecene without any rhodium leaching. It could also be used in the absence of a solvent, as observed in the hydroformylation of 1-decene. Although the best system was based on a hybrid microporous matrix, no straightforward correlation between matrix composition, condensation degree and surface properties could be found.

Keywords: sol-gel process, hydroformylation, rhodium

\section{Introduction}

Hydroformylation of olefins is the largest scale homogeneous catalytic reaction. ${ }^{1}$ Homogeneous catalysis, however, presents several drawbacks, in particular the recovering of the catalyst at the end of the process, warranting a search for two-phase or immobilized catalysts. In the last years, the sol-gel method has been applied as an alternative to immobilize soluble catalysts, using either inorganic ${ }^{2}$ or hybrid ${ }^{3}$ matrices. Recently, we reported the use of this approach to prepare rhenium-, molybdenumand vanadium-based epoxidation catalysts, ${ }^{4-6}$ as well as ruthenium- and rhodium-based catalysts for the hydrogenation and hydroformylation of olefins, respectively. ${ }^{7,8}$ Depending on the characteristics of the matrix, leaching-free systems could be prepared even when

* e-mail: rbuffon@iqm.unicamp.br the transition metal complex was just physically entrapped inside the porous system. In the case of rhodium complexes containing a diphosphine and no ligand bearing a hydrolysable group, only a microporous matrix would lead to recyclable catalysts. ${ }^{8} \mathrm{An}$ interesting and robust rhodium catalyst system containing a xanthene-based hydrolysable ligand was previously described, ${ }^{9}$ but the matrix was not characterized. We wish to report here some results concerning the immobilization of rhodium complexes in silica matrices prepared by the sol-gel method using ligands bearing hydrolysable groups and their use in the hydroformylation of olefins.

\section{Experimental}

Complexes $[\mathrm{Rh}(\mathrm{OMe})(\mathrm{cod})]_{2},{ }^{10}[\mathrm{Rh}(\mathrm{cod})(\mathrm{acac})],{ }^{11}$ $\left[\mathrm{Rh}(\mathrm{cod})\left(\mathrm{PPh}_{3}\right)_{2}\right]^{+} \mathrm{BPh}_{4}^{-},{ }^{-12}$ ligands $\mathrm{Ph}_{2} \mathrm{P}\left(\mathrm{CH}_{2}\right)_{2} \mathrm{Si}(\mathrm{OMe})_{3},{ }^{13}$ $\mathrm{Ph}_{2} \mathrm{P}\left(\mathrm{CH}_{2}\right)_{2} \mathrm{~S}\left(\mathrm{CH}_{2}\right)_{3} \mathrm{Si}(\mathrm{OMe})_{3},{ }^{14}$ and the co-condensation 
agent 1,4-bis(triethoxysilyl)benzene ${ }^{15}$ were prepared according to the literature. The co-condensation agent 1,2bis(triethoxysilyl)ethane was prepared by metathesis of (triethoxysilyl)vinyl (Aldrich) followed by hydrogenation. $\left[\mathrm{Rh}(\mathrm{CO})_{2}(\mathrm{acac})\right]$ and XANTPHOS were purchased from Strem Chemicals; $\mathrm{HS}\left(\mathrm{CH}_{2}\right)_{3} \mathrm{Si}(\mathrm{OMe})_{3}$, from Aldrich. THF (Merck) was dried over $\mathrm{Na} /$ benzophenone just before use.

\section{Catalyst preparation}

In a typical preparation, $5 \mathrm{mg}(\sim 10 \mathrm{mmol})$ of the rhodium precursor and a corresponding equivalent of the ligand ([P]:[Rh]=2:1) were added to a $50 \mathrm{~mL}$ Schlenk flask containing $6 \mathrm{~mL}$ of THF. The solution was kept under stirring for $15 \mathrm{~min}$, followed by the addition of $2 \mathrm{~mL}$ (11.10 mmol) of deionized water, $2 \mathrm{~mL}(13.56 \mathrm{mmol})$ of TMOS (tetramethylorthosilicate), $1 \mathrm{~mL}(\sim 3.4 \mathrm{mmol})$ of the co-condensation agent (in the case of hybrid matrices), methanol ( $c a .1 \mathrm{~mL}$, amount needed to obtain a clean solution) and 4 drops of a $3 \mathrm{wt}$. $\%$ solution of $(\mathrm{AcO})_{2} \mathrm{Sn}(\mathrm{Bu})_{2}$ in polydimethylsiloxane (Dow Corning). The solution was stirred for $15 \mathrm{~min}$ and allowed to stand until gelation (from one night to 8 days, depending on the case). The gel thus obtained was dried under vacuum, washed with $\mathrm{CH}_{2} \mathrm{Cl}_{2}$ in a Soxhlet and dried again under vacuum at room temperature. The resulting yellow-orange materials were stored under air at room temperature.

\section{Catalytic experiments}

All catalytic experiments were performed in a $100 \mathrm{~mL}$ stainless steel Parr reactor. The reaction temperature was kept at $80^{\circ} \mathrm{C}$ and the solution was stirred at $300 \mathrm{rpm}$. In a typical experiment, $2-5 \mu \mathrm{mol}$ of the rhodium complex ( $250 \mathrm{mg}$ of the catalyst), $0.28 \mathrm{~g}(2-5 \mathrm{mmol})$ of 1-hexene ([Rh]/[olefin] 1/1000), $0.1 \mathrm{~g}$ of cyclooctane (internal standard) and $30 \mathrm{~mL}$ of THF (solvent) were employed. The reactor was first purged with $\mathrm{H}_{2}$, and then pressurized at 50 bar $\left(\mathrm{CO} / \mathrm{H}_{2}=1 / 1\right)$. For recycling experiments, the catalyst was separated by filtration, washed in a Soxhlet with $\mathrm{CH}_{2} \mathrm{Cl}_{2}$, dried under vacuum and used in a new run. All procedures were performed under air. GC analyses were carried out in an HP5890 series II gas chromatograph, equipped with an HP5 capillary column (50 m x $0.2 \mathrm{~mm}$ ) and a flame ionization detector. Products were quantified using calibration curves obtained with standard solutions.

\section{Catalyst characterization}

Nitrogen adsorption isotherms were determined at $-196{ }^{\circ} \mathrm{C}$ with a Micromeritics ASAP 2010 automated porosimeter. All calculations were performed using the associated Micromeritics software. Samples were degassed at $80{ }^{\circ} \mathrm{C}$ for a minimum of $24 \mathrm{~h}$ prior to measurements.

Rhodium concentrations were determined through ICPAES analyses (Perkin-Elmer Optima 3000 DV).

TEM images were obtained on a Zeiss CEM-902 apparatus equipped with a CCD-Proscan camera and a high speed/slow scan system controller. The samples were suspended in iso-propanol and dispersed on carbon-coated copper grids.

${ }^{29} \mathrm{Si}$ MAS NMR spectra were recorded on a Bruker AC 300 spectrometer using zirconia rotors and the following conditions: delay between each scan $=15 \mathrm{~s}$; acquisition time $=0.1 \mathrm{~s}$. Typically, 5000 scans were accumulated. Solution ${ }^{31} \mathrm{P}$ NMR spectra were recorded on a Gemini 300 $\mathrm{P}$ instrument at $121.5 \mathrm{MHz}$, in $\mathrm{CDCl}_{3}$.

\section{Results and Discussion}

In order to determine the effects of the nature of the rhodium complex on the properties of the resulting matrix, four different precursors, viz. $[\mathrm{Rh}(\mathrm{OMe})(\mathrm{cod})]_{2}$, $[\mathrm{Rh}(\mathrm{cod})(\mathrm{acac})],\left[\mathrm{Rh}(\mathrm{CO})_{2}(\mathrm{acac})\right]$ and $\left[\mathrm{Rh}(\mathrm{cod})\left(\mathrm{PPh}_{3}\right)_{2}\right]^{+} \mathrm{BPh}_{4}^{-}$, as well as three ligands bearing hydrolysable groups, viz. $\mathrm{HS}\left(\mathrm{CH}_{2}\right)_{3} \mathrm{Si}(\mathrm{OMe})_{3} \quad, \quad \mathrm{Ph}_{2} \mathrm{P}\left(\mathrm{CH}_{2}\right)_{2} \mathrm{Si}(\mathrm{OMe})_{3}$ and $\mathrm{Ph}_{2} \mathrm{P}\left(\mathrm{CH}_{2}\right)_{2} \mathrm{~S}\left(\mathrm{CH}_{2}\right)_{3} \mathrm{Si}(\mathrm{OMe})_{3}$ were employed. The acaccontaining complexes were expected to lead to mesoporous matrices, which would facilitate diffusion of the substrates. ${ }^{8}$ The ligand $\mathrm{HS}\left(\mathrm{CH}_{2}\right)_{3} \mathrm{Si}(\mathrm{OMe})_{3}$ would lead to a dimer whose anchoring to silica has been reported to give an almost leachless system. ${ }^{16}$ Two co-condensation agents were also tested, 1,4-bis(triethoxysilyl)benzene and 1,2bis(triethoxysilyl)ethane, aiming to reduce the degree of 3Dcross-linking, decreasing the rigidity and improving the swelling properties of the resulting matrices. The expected immobilized rhodium species are depicted in Scheme 1. The structures of systems I+XANTPHOS, and III, IV are proposed on the basis of their ${ }^{31} \mathrm{P}$ NMR spectra obtained before gelation. For systems II and III, the free acac' ligand would deprotonate a silanol group form the surface, producing a $\equiv \mathrm{SiO}^{-}$anion. ${ }^{9}$ The same anion could be formed in system IV via a reaction between $\mathrm{BPh}_{4}^{-}$and a silanol group. It must be kept in mind, however, that the ionic species depicted in Scheme 1 would be present only in a fresh catalyst: under hydroformylation conditions, the cationic species are neutralized ${ }^{17}$ and systems II to IV would eventually be of the type $\left[\mathrm{RhH}(\mathrm{CO})_{\mathrm{x}} \mathrm{L}_{2}\right]$, where $\mathrm{L}=$ is a neutral ligand bearing $\mathrm{P}$ or $\mathrm{S}$ as donor atoms.

Systems based on inorganic matrices are labeled with the index $\mathbf{a} ; \mathbf{b}$ and $\mathbf{c}$ are related to hybrid matrices based on 1,4-bis(triethoxysilyl)benzene and 1,2bis(triethoxysilyl)ethane, respectively. All systems were 


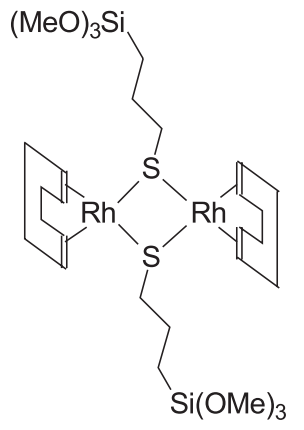

I

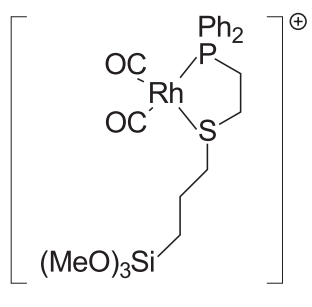

II

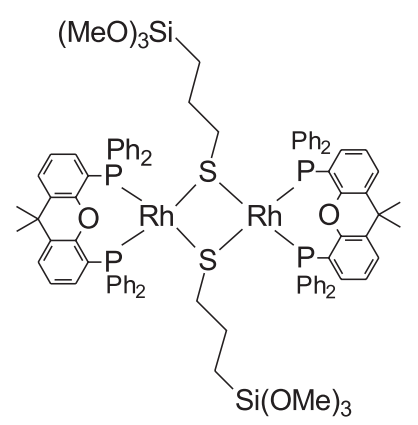

I + XANTPHOS

${ }^{31}$ P NMR: $22.8 \mathrm{ppm}$

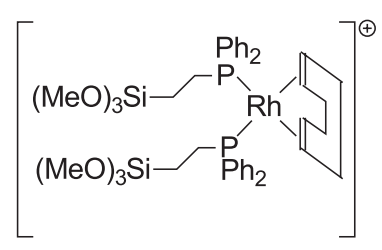

III and IV

${ }^{31}$ P NMR: $33.2 \mathrm{ppm}$

Scheme 1.

characterized by ${ }^{29} \mathrm{Si}$ MAS NMR and, whenever possible, also by nitrogen adsorption/desorption isotherms.

\section{Catalyst characterization}

The nitrogen adsorption/desorption isotherms of catalysts Ia, IIb and IIIa are of type I (IUPAC
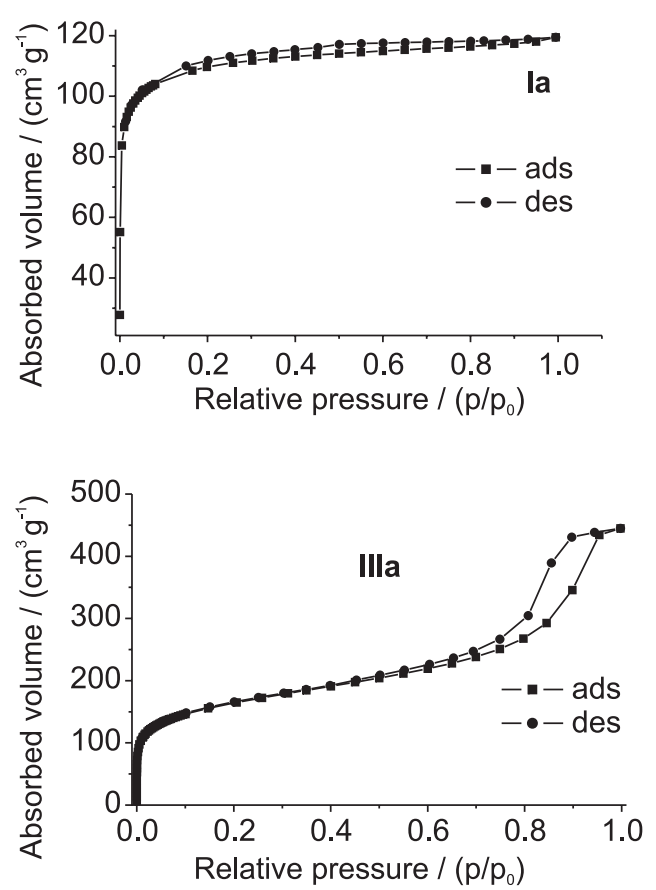

classification), ${ }^{18}$ typical of microporous systems (Figure 1). A small hysteresis is clearly observed only for catalyst IIb, suggesting that the pores are mainly smooth and cylindrical, with a low contribution of mesopores. ${ }^{19}$ The Horvath-Kawazoe differential pore volume plots for these catalysts are shown in Figure 2. Catalyst IVa is characterized by a type IV isotherm (mesoporous) with a small contribution of micropores: the volume adsorbed at the lowest relative pressure represents $\sim 20 \%$ of the total pore volume (Figure 1). Its BJH adsorption pore size distribution is shown in Figure 2. BET surface areas, pore volumes and average pore size determined from the isotherms, along with the final rhodium loading, are presented in Table 1. The amount of immobilized rhodium was always smaller than the added one, with the excess being washed away during Soxhlet extractions, which were repeated until a clean solution was obtained.

We failed to obtain isotherms for catalysts $\mathbf{I b}$ and $\mathbf{I c}$. They were, therefore, characterized by transmission electron microscopy. Taking into account that these materials were able to entrap a relatively large amount of rhodium without leaching in the catalytic experiments (vide infra), their TEM micrographs, shown in Figure 3, suggest a dense structure with packed microporous domains.

${ }^{29}$ MAS Si NMR spectra could provide a relationship between the condensation degree of TMOS and the porosity of the corresponding material. Figure 4 shows the spectra obtained for three different samples: an inorganic matrix (catalyst Ia); a hybrid matrix containing 1,4-
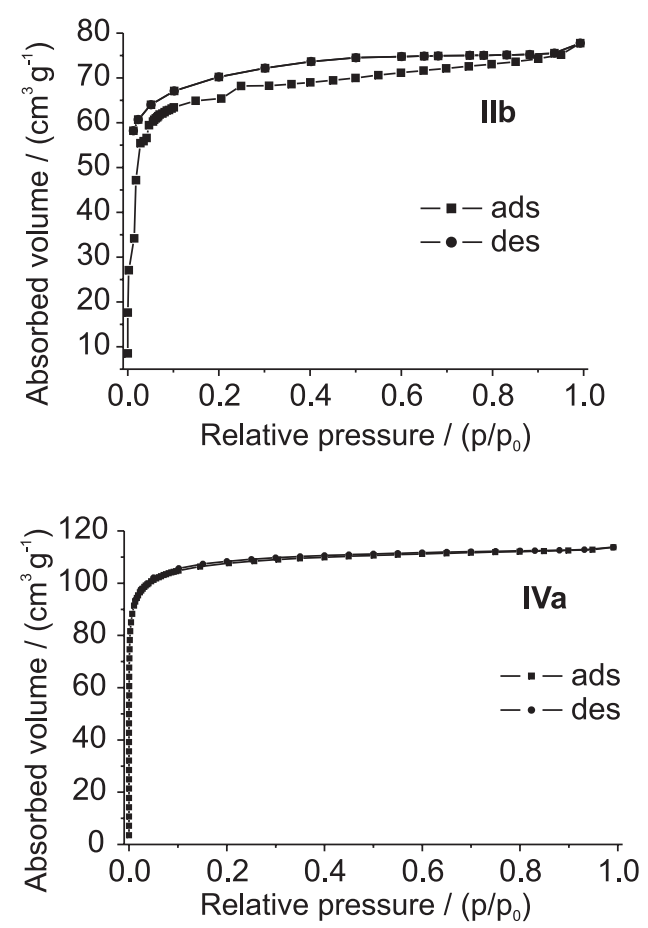

Figure 1. Nitrogen adsorption/desorption isotherms for some systems. 

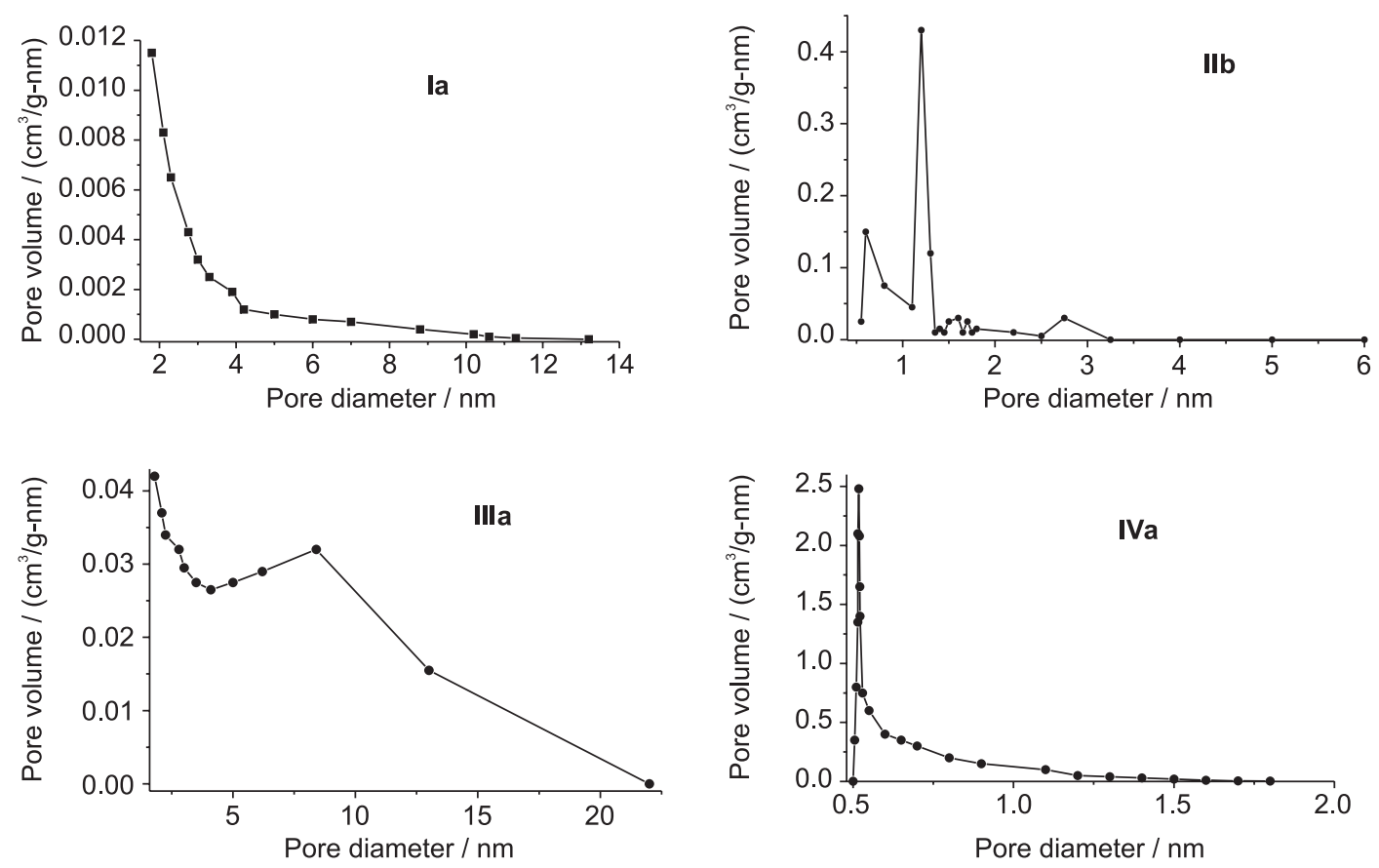

Figure 2. Pore size distribution for some systems.

Table 1. Composition and surface characteristics of the catalysts

\begin{tabular}{|c|c|c|c|c|c|c|c|}
\hline System & Complex & Ligand $^{\mathrm{a}}$ & $\begin{array}{c}\text { Co-condensation } \\
\text { Agent }\end{array}$ & $\begin{array}{c}\mathrm{Rh} \\
\text { wt. } \%\end{array}$ & $\begin{array}{c}\text { Area } \\
\text { BETm }^{2} \mathrm{~g}^{-1}\end{array}$ & $\begin{array}{c}\text { Pore } \\
\text { diameternm }\end{array}$ & $\begin{array}{c}\text { Pore } \\
\text { volume } \mathrm{cm}^{3} \mathrm{~g}^{-1}\end{array}$ \\
\hline Ia & {$[\mathrm{Rh}(\mathrm{OMe})(\mathrm{cod})]_{2}$} & $\mathrm{Si}-\mathrm{SH}$ & - & 0.35 & 340 & $3.55^{\mathrm{b}}$ & $0.18^{\mathrm{b}}$ \\
\hline $\mathbf{I a}+\mathbf{X}$ & {$[\mathrm{Rh}(\mathrm{OMe})(\mathrm{cod})]_{2}$} & $\mathrm{Si}-\mathrm{SH}+\mathrm{XANTPHOS}$ & - & 0.31 & & & \\
\hline Ib & {$[\mathrm{Rh}(\mathrm{OMe})(\mathrm{cod})]_{2}$} & $\mathrm{Si}-\mathrm{SH}$ & $(\mathrm{EtO})_{3} \mathrm{SiPhSi}(\mathrm{OEt})_{3}$ & 0.22 & & & \\
\hline $\mathbf{I b}+\mathbf{X}$ & {$[\mathrm{Rh}(\mathrm{OMe})(\operatorname{cod})]_{2}$} & $\mathrm{Si}-\mathrm{SH}+\mathrm{XANTPHOS}$ & $(\mathrm{EtO})_{3} \mathrm{SiPhSi}(\mathrm{OEt})_{3}$ & 0.17 & & & \\
\hline Ic & {$[\mathrm{Rh}(\mathrm{OMe})(\mathrm{cod})]_{2}^{2}$} & $\mathrm{Si}-\mathrm{SH}$ & $(\mathrm{EtO})_{3} \mathrm{Si}\left(\mathrm{CH}_{2}\right)_{2} \mathrm{Si}(\mathrm{OEt})_{3}$ & 0.15 & & & \\
\hline IIb & {$\left[\mathrm{Rh}(\mathrm{CO})_{2}(\mathrm{acac})\right]$} & Si-PS & $(\mathrm{EtO})_{3} \mathrm{SiPhSi}(\mathrm{OEt})_{3}$ & 0.24 & 250 & $1.11^{\mathrm{b}}$ & $0.12^{\mathrm{b}}$ \\
\hline IIIa & {$[\operatorname{Rh}(\operatorname{cod})(\mathrm{acac})]$} & $\mathrm{Si}-\mathrm{PPh}_{2}$ & - & 0.09 & 600 & $6.65^{\mathrm{c}}$ & $0.69^{c}$ \\
\hline IVa & {$\left[\mathrm{Rh}(\operatorname{cod})\left(\mathrm{PPh}_{3}\right)_{2}\right]^{+}$} & $\mathrm{Si}^{-} \mathrm{PPh}_{2}$ & - & 0.02 & 400 & $0.64^{\mathrm{b}}$ & $0.18^{\mathrm{b}}$ \\
\hline
\end{tabular}

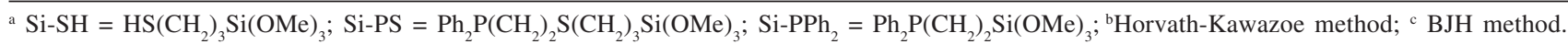

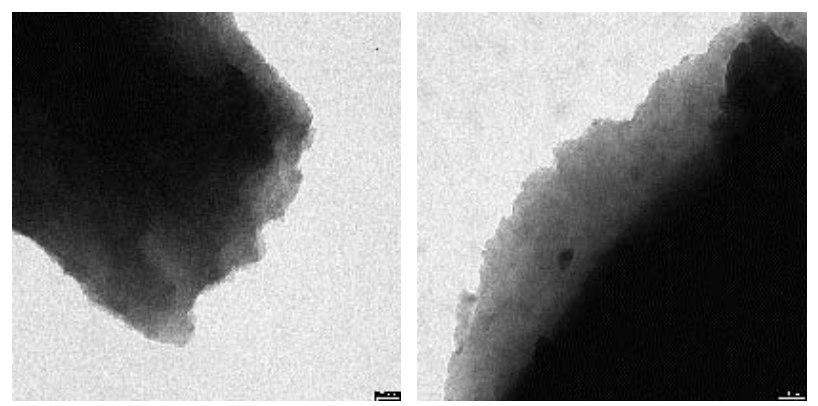

Figure 3. TEM micrographs for systems Ib (left) and Ic (right).

bis(triethoxysilyl)benzene (IIlb) and a hybrid matrix based on 1,2-bis(triethoxysilyl)ethane (Ic). Table 2 shows the concentration of each type of silicon site: $\mathrm{Q}^{2}\left[=\mathrm{Si}(\mathrm{OH})_{2}\right.$, $\delta \sim-91] ; \mathrm{Q}^{3}[\equiv \mathrm{Si}(\mathrm{OH}), \delta \sim-101] ; \mathrm{Q}^{4}[\equiv \mathrm{Si}-\mathrm{O}-\mathrm{Si} \equiv, \delta \sim-109] ;$ $\mathrm{T}^{1}\left[-\mathrm{Si}(\mathrm{OR})_{2} \mathrm{R}^{\prime}, \delta \sim-62\right.$ for systems $\mathbf{b} ; \sim-45$ for system $\left.\mathbf{c}\right]$; $\mathrm{T}^{2}[=\mathrm{Si}(\mathrm{OR}) \mathrm{R}$ ', $\delta \sim-71$ for systems $\mathbf{b} ; \sim-53$ for system $\mathbf{c}]$

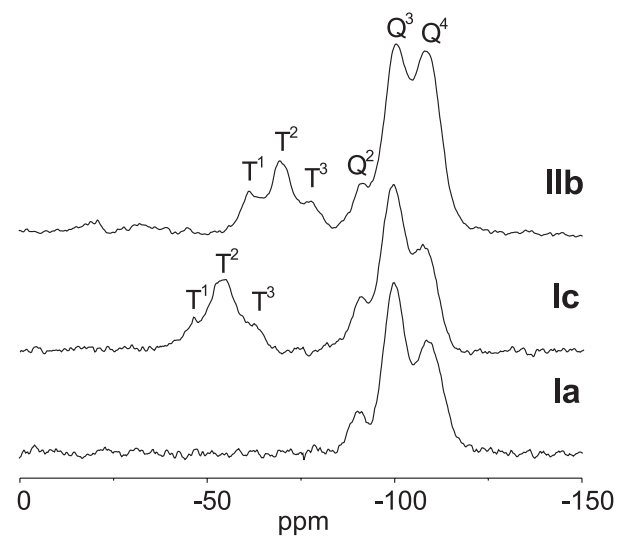

Figure 4. Characteristic ${ }^{29} \mathrm{Si}$ MAS NMR spectra.

and $\mathrm{T}^{3}\left[\equiv \mathrm{Si}-\mathrm{R}^{\prime}, \delta \sim-79\right.$ for systems $\mathbf{b} ; \sim-63$ for system $\left.\mathbf{c}\right]$. Signals corresponding to silicon atoms from the ligands could never be observed, probably due to the very low 
Table 2. Concentration of silicon sites as obtained by ${ }^{29} \mathrm{Si}$ MAS NMR

\begin{tabular}{lccccccccc}
\hline Sample & $\mathrm{T}^{1}$ & $\mathrm{~T}^{2}$ & $\mathrm{~T}^{3}$ & $\mathrm{Q}^{2}$ & $\mathrm{Q}^{3}$ & $\mathrm{Q}^{4}$ & $\mathrm{~T}^{2} / \mathrm{T}^{1}$ & $\mathrm{Q}^{4} / \mathrm{Q}^{3}$ & $\mathrm{Q}^{4} / \mathrm{Q}^{2}$ \\
\hline Ia & - & - & - & 3.4 & 58.1 & 38.5 & - & 0.66 & 11.3 \\
Ia + XANTPHOS & - & - & - & 13.4 & 55.0 & 31.6 & - & 0.57 & 2.4 \\
Ib & 13.2 & 12.6 & 4.3 & 5.8 & 36.8 & 27.4 & 0.95 & 0.74 & 4.7 \\
Ib + XANTPHOS & 4.6 & 17.4 & 5.3 & 5.4 & 36.3 & 31.0 & 3.8 & 0.85 & 5.7 \\
Ic & 0.8 & 25.1 & 3.7 & 2.6 & 42.6 & 25.3 & 31.4 & 0.59 & 9.7 \\
IIb & 5.0 & 14.0 & 1.9 & 1.7 & 39.4 & 38.0 & 2.8 & 0.96 & 22.4 \\
IIIa & - & - & - & 7.8 & 39.5 & 52.6 & - & 1.33 & 6.7 \\
IVa & - & - & - & 5.5 & 40.9 & 53.6 & - & 1.31 & 9.7 \\
\hline
\end{tabular}

concentration of such ligands relatively to TMOS (molar ratios: 1:1400 for system IIb; 1:700 for systems I, III and IV). Taking into account that the molar ratio [TMOS]/[cocondensation agent] was kept constant $(=4)$ in all preparations, a $\Sigma \mathrm{Q}^{\mathrm{i} /} / \Sigma \mathrm{T}^{\mathrm{i}} \sim 2 / 1$ was expected. However, such ratios varied from 2.3 (Ib) to 3.8 (IIb), suggesting that some amount of co-condensation agent was not incorporated into the matrix and was washed away during the Soxhlet treatment.

Comparing the $\mathrm{Q}^{4} / \mathrm{Q}^{3}$ ratio for systems $\mathbf{I}$, the addition of a co-condensation agent appears to have little effect on the condensation degree of TMOS. The $\mathrm{Q}^{4} / \mathrm{Q}^{2}$ ratio, however, is strongly affected, with a high increase in the relative concentration of $\mathrm{Q}^{2}$ sites, in particular for system Ib. For the hybrid matrices, $\mathrm{T}^{2}$ sites predominate in the case of systems Ic and IIb; system Ib, however, presents a $\mathrm{T}^{2} / \mathrm{T}^{1}$ ratio close to one. $\mathrm{T}^{3}$ sites are always minority. These results show that the overall 3D-cross-linking degree is indeed strongly affected by the addition of a cocondensation agent, but not always to the same extent. The highest degree of TMOS condensation is observed for systems IIIa and IVa, the only ones presenting $Q^{4} / Q^{3}$ ratios higher than 1.

Nevertheless, neither the condensation degree of TMOS nor the presence of a co-condensation agent can be directly correlated with surface area, pore diameter or pore volume. It seems that the nature of the rhodium complex plays an important role in determining the final characteristics of the matrix. Evidences are the changes in $\mathrm{Q}^{4} / \mathrm{Q}^{2}$ and $\mathrm{T}^{2} / \mathrm{T}^{1}$ ratios when system Ia and $\mathbf{I b}$, respectively, were prepared in presence of the ligand XANTPHOS (Table 2). On the other hand, in a previous work ${ }^{8}$ it was observed that neutral rhodium complexes bearing an acac ligand, or even cationic rhodium complexes always led to mesoporous matrices. It should be noted, however, the absence of a hydrolysable ligand in those systems. Therefore, the microporosity observed for systems IIb and IVa was a little surprising. Also surprising were the results obtained for systems IIIa and IVa: upon reaction between the precursor complex and the ligand, the same species should be immobilized (Scheme 1) but the matrices are strongly different. This result clearly implies that the nature of the free ligand plays an important role in determining the final characteristics of the matrix. The only similarity was the very small amount of entrapped rhodium species. Whether this fact is related to the high condensation degree of TMOS or to a possible cleavage of the hydrolysable ligand cannot be decided yet. However, a high condensation degree might force the hydrolysable ligand to the outside surface, which could account for the high leaching of rhodium in the absence of a chelating ligand.

\section{Catalytic activity}

All systems were tested in the hydroformylation of 1-hexene and the results are shown in Table 3. $\mathrm{PPh}_{3}\left(\left[\mathrm{PPh}_{3}\right] /\right.$ $[\mathrm{Rh}]=5 / 1)$ was added to systems $\mathbf{I}$ since the precursor complex is not active in hydroformylation. ${ }^{20}$ When analyzing systems $\mathbf{I}$, the importance of the matrix composition is clear as the catalyst based on the inorganic matrix (Ia) did not present any activity; for a hybrid matrix based on 1,2-bis(triethoxysilyl)ethane (Ic) the activity was very low but the system prepared with the co-condensation agent bis(triethoxysilyl)benzene (Ib) presented a reasonable activity and could be used in at least three runs without any rhodium leaching. The lack of activity observed for system Ia might be due to a non-interaction between the rhodium complex and the added $\mathrm{PPh}_{3}$. Therefore, a new gel was prepared by addition of the chelating ligand XANTPHOS ([XANTPHOS $] /[\mathrm{Rh}]=2 / 1$ ) to the initial solution containing $[\mathrm{Rh}(\mathrm{OMe})(\mathrm{cod})]_{2}$ and $\mathrm{HS}\left(\mathrm{CH}_{2}\right)_{3} \mathrm{Si}(\mathrm{OMe})_{3}$. For comparison, a sample of system $\mathbf{I b}$ was prepared in the same way. Both systems were active although the observed $\mathrm{n} / \mathrm{i}$ ratios (ratio between normal and branched aldehydes) were rather lower than those reported for monomeric rhodium catalysts containing the ligand XANTPHOS $(\mathrm{n} / \mathrm{i}>50){ }^{21}$

Although system IVa presented the highest $\mathrm{n} / \mathrm{i}$ ratio observed in this work, its catalytic activity was very low. This may be due to mass transfer limitations arising from a very 
Table 3. Catalytic performance in the hydroformylation of 1-hexene

\begin{tabular}{|c|c|c|c|c|c|c|c|}
\hline System & Rh wt.\% & Run & Conv. $\%^{\mathrm{b}}$ & $\mathrm{n} / \mathrm{i}^{\mathrm{c}}$ & $\mathrm{H} / \mathrm{I}^{\mathrm{d}}$ & $\mathrm{TON}^{\mathrm{e}}$ & $\mathrm{Rh}$ leaching \\
\hline $\mathbf{I a}^{\mathrm{f}}$ & 0.35 & 1 & 0 & - & - & 0 & no \\
\hline $\mathbf{I a}+\mathbf{X}$ & 0.31 & 1 & 22 & 1.9 & 1.1 & 220 & no \\
\hline \multirow[t]{3}{*}{$\mathbf{I b}^{\mathrm{f}}$} & 0.22 & 1 & 44 & 1.9 & 1.5 & 440 & no \\
\hline & & 2 & 30 & 1.8 & 1.1 & 300 & no \\
\hline & & 3 & 30 & 2.1 & 1.1 & 300 & no \\
\hline $\mathbf{I b}+\mathbf{X}$ & 0.17 & 1 & 38 & 2.0 & 1.7 & 380 & no \\
\hline $\mathbf{I} \mathbf{c}^{\mathrm{f}}$ & 0.15 & 1 & 3 & 1.2 & 0.7 & 30 & no \\
\hline \multirow[t]{4}{*}{ Iib } & 0.24 & 1 & 57 & 2.0 & 1.6 & 570 & no \\
\hline & & 2 & 51 & 1.8 & 1.5 & 510 & no \\
\hline & & 3 & 25 & 1.9 & 1.3 & 250 & no \\
\hline & & 4 & 18 & 2.0 & 1.4 & 180 & no \\
\hline IIIa & 0.09 & 1 & 91 & 1.0 & 1.5 & 910 & high \\
\hline Iva & 0.02 & 1 & 7.4 & 2.5 & - & 74 & no \\
\hline
\end{tabular}

${ }^{a}$ Reaction conditions: $[\mathrm{Rh}] /[$ olefin $]=1 / 1000 ; 50$ bar $\left([\mathrm{CO}] /\left[\mathrm{H}_{2}\right]=1 / 1\right) ; 80^{\circ} \mathrm{C} ; 24 \mathrm{~h}$; solvent: THF; ${ }^{\mathrm{b}}$ conversion to hydroformylation products; ${ }^{\mathrm{c}}$ ratio between normal and branched aldehydes; ${ }^{\mathrm{d}}$ ratio between hydroformylation and isomerization products; ${ }^{\mathrm{e}} \mathrm{TON}=$ mol of aldehydes per mol of rhodium sites; ${ }^{\mathrm{f}} \mathrm{PPh}_{3}$ added to the reaction mixture $\left(\left[\mathrm{PPh}_{3}\right] /[\mathrm{Rh}]=5 / 1\right) ; \mathrm{X}=\mathrm{XANTPHOS}$.

small pore diameter of the matrix (Figure 2). In contrast, the activity of system IIIa was due to leached rhodium, not retained by a matrix characterized by a large distribution of mesopores (Figure 2). System IIb turned out to be more active than all other systems prepared in this work. It was active in at least four runs, with a total TON of 1510, albeit some deactivation from run to run. When tested in the hydroformylation of 1-decene in the absence of a solvent $([\mathrm{Rh}] /[$ olefin $]=1 / 4540)$, a TON of 2450 was observed after $24 \mathrm{~h}(\mathrm{n} / \mathrm{i}=1.5 ; \mathrm{H} / \mathrm{I}=2.7)$. It was also active in the hydroformylation of 1-octadecene: using the same conditions employed for 1-hexene, a TON $=530$ was obtained (close to the 570 value observed for 1-hexene in the first run, Table 3), with $n / i=2.3$ and $H / I=1.7$. Thus, in spite of a microporous matrix, higher linear substrates could be hydroformylated. Taking into account that a chelating hydrolysable ligand was employed, the location of the rhodium complex (inside the porous system or on the external surface of the matrix) is a question that could be raised. Therefore, system IIb was tested in the hydroformylation of limonene, a voluminous substrate (volume $\sim 0,435 \mathrm{~nm}^{3}$ ). ${ }^{22}$ Within $24 \mathrm{~h}$ no reaction was observed. In the same experimental conditions, with the system $\left[\mathrm{RhCl}(\mathrm{CO})_{2}\right]_{2} / \mathrm{BINAP}$ in solution a $21 \%$ conversion to hydroformylation products was obtained in $4 \mathrm{~h}$. These results strongly suggest that the complex is indeed inside the porous system of the matrix and that the deactivation observed in successive runs is due to a degradation of the complex upon manipulation after each reaction (always performed under air).

\section{Conclusions}

Although it seems that the nature of the rhodium complex plays an important role in determining the final characteristics of the matrix, no direct correlation between rhodium complex, matrix composition, condensation degree and surface properties could be found. Therefore, a straightforward way to prepare a desired matrix with any metal complex remains to be found. The system based on $\left[\mathrm{Rh}(\mathrm{CO})_{2}(\mathrm{acac})\right] / \mathrm{Ph}_{2} \mathrm{P}\left(\mathrm{CH}_{2}\right)_{2} \mathrm{~S}\left(\mathrm{CH}_{2}\right)_{3} \mathrm{Si}(\mathrm{OMe})_{3}$ was active in the hydroformylation of 1-decene in the absence of a solvent, without any rhodium leaching. In spite of its microporous matrix, this catalyst was also active in the hydroformylation of 1-octadecene. The lack of any activity in the hydroformylation of limonene suggests that the complex is indeed entrapped inside the porous system of the matrix.

\section{Acknowledgements}

Financial support from FAPESP, as well as a fellowship to J.D.R.C., are gratefully acknowledged.

\section{References}

1. Cornils, B.; Herrmann, W.A.; Applied Homogeneous Catalysis with Organometallic Compounds, VCH: New York, Vol. 1, 1996.

2. Blum, J.; Avnir, D.; Schumann, H.; Chemtech 1999, 29, 32.

3. Lindner, E.; Schneller, T.; Auer, F.; Mayer, H.A.; Angew. Chem. Int. Ed. 1999 38, 2155.

4. Dallmann, K.; Buffon, R.; Catal. Commun. 2000 1, 9.

5. Teixeira, S.; Dallmann, K.; Schuchardt, U.; Buffon, R.; J. Mol. Catal. A: Chem. 2002, 182-183, 167.

6. Pellegrino, R.B.; Buffon, R.; J. Braz. Chem. Soc. 2004, 15, 527.

7. Dallmann, K.; Buffon, R.; J. Mol. Catal. A: Chem. 2002, 185, 187. 
8. Campos, J.D.R.; Buffon, R.; New J. Chem. 2003, 27, 446.

9. Sanden, A.J.; van der Veen, L.A.; Reek, J.N.H.; Kamer, P.C.J.; Lutz, M.; Spek, A.L.; van Leeuwen, P.W.N.M.; Angew. Chem. Int. Ed. 1999, 38, 3231.

10. Uson, R.; Oro, L.A.; Cabeza, J.A.; Inorg. Synth. 1985, 23, 127.

11. Cramer, R.; J. Am. Chem. Soc. 1964, 86, 217.

12. Schrock, R.R.; Osborn, J.A.; J. Am. Chem. Soc. 1971, 93, 2397.

13. Niebergall, V.W.; Makromol. Chem. 1962, 52, 218.

14. Capka, M.; Czakoová, M.; Hillerová, E.; Paetzold, E.; Oehme, G.; J. Mol. Catal. A: Chem. 1995, 104, L123.

15. Loy, D.A.; Jamison, G.M.; Baugher, B.M.; Myers, S.A.; Assink, R.A.; Shea, K.J.; Chem. Mater. 1996, 8, 656.

16. Gao, H.; Angelici, R.J.; Organometallics 1998, 17, 3063.

17. Pàmies, O.; Net, G.; Widhalm, M.; Ruiz, A.; Claver, A.; J. Organomet. Chem. 1999, 587, 136.
18. Sing, K.S.W.; Everett, D.H.; Haul, R.A.; Moscou, L.; Pierotti, R.A.; Rouquerol, J.; Siemieniewska, T.; Pure Appl. Chem. 1985, 57, 603.

19. Brinker, C.J.; Scherer, G.W.; Sol-Gel Science: The Physics and Chemistry of Sol-Gel Processing, Academic Press: San Diego, 1990, pp 522-525.

20. Angelici, R.J.; Gao, H.; J. Mol. Catal. A: Chem. 1999, 145, 83.

21. Kranenburg, M.; van der Burgt, Y.E.M.; Kamer, P.C.J.; van Leeuwen, P.W.N.M.; Organometallics 1995, 14, 3081.

22. Calculated using GAUSSIAN 1998 (Revision A.9) computational programs from HF optimized geometries.

Received: April 27, 2004

Published on the web: November 12, 2004

FAPESP helped in meeting the publication costs of this article. 